\title{
Intercircuit Control via Rhythmic Regulation of Projection Neuron Activity
}

\author{
Debra E. Wood, ${ }^{1,2}$ Yair Manor, ${ }^{3}$ Farzan Nadim, ${ }^{4}$ and Michael P. Nusbaum ${ }^{1}$ \\ ${ }^{1}$ Department of Neuroscience, University of Pennsylvania School of Medicine, Philadelphia, Pennsylvania 19104-6074, ${ }^{2}$ Department of Biology, Case \\ Western Reserve University, Cleveland, Ohio 44106, ${ }^{3}$ Zlotowski Center for Neuroscience and Department of Life Science, Ben-Gurion University, Beer- \\ Sheva 84105, Israel, and ${ }^{4}$ Department of Biological Sciences, Rutgers University, and Department of Mathematical Sciences, New Jersey Institute of \\ Technology, Newark, New Jersey 07102
}

Synaptic feedback from rhythmically active neuronal circuits commonly causes their descending inputs to exhibit the rhythmic activity pattern generated by that circuit. In most cases, however, the function of this rhythmic feedback is unknown. In fact, generally these inputs can still activate the target circuit when driven in a tonic activity pattern. We are using the crab stomatogastric nervous system (STNS) to test the hypothesis that the neuronal circuit-mediated rhythmic activity pattern in projection neurons contributes to intercircuit regulation. The crab STNS contains an identified projection neuron, modulatory commissural neuron 1 (MCN1), whose tonic stimulation activates and modulates the gastric mill (chewing) and pyloric (filtering of chewed food) motor circuits in the stomatogastric ganglion (STG). During tonic stimulation of $\mathrm{MCN1}$, the pyloric circuit regulates both gastric mill cycle frequency and gastropyloric coordination via a direct synapse onto a gastric mill neuron in the STG. However, when MCN1 is spontaneously active, it has a pyloric-timed activity pattern attributable to synaptic input from the pyloric circuit. This pyloric-timed activity in MCN1 provides the pyloric circuit with a second pathway for regulating the gastric mill rhythm. At these times, the direct STG synapse from the pyloric circuit to the gastric mill circuit is not necessary for pyloric regulation of the gastric mill rhythm. However, in the intact system, these two pathways play complementary roles in this intercircuit regulation. Thus, one role for rhythmicity in modulatory projection neurons is to enable them to mediate the interactions between distinct but related neuronal circuits.

Key words: central pattern generator; neuromodulation; stomatogastric ganglion; pyloric circuit; gastric mill circuit; modulatory projection neuron

\section{Introduction}

Projection neurons that activate rhythmically active neuronal circuits commonly switch from a tonic to rhythmic activity pattern once their target circuit is activated as a result of feedback they receive from that circuit (Weeks, 1981; Dubuc and Grillner, 1989; Kasicki et al., 1989; Frost and Katz, 1996; Perrins and Weiss, 1996; Deliagina et al., 2000). Despite this rhythmic activity pattern, tonic stimulation of these projection neurons is often sufficient to elicit rhythmic activity from the target circuit, suggesting that these inputs provide no timing cues to the activated circuit. It has been suggested that the rhythmic activity exhibited by these projection neurons helps maintain their activity and thereby contributes to maintaining circuit activity (Weeks, 1981). However, the function(s) of the rhythmic activity pattern in such projection neurons remains to be determined.

To examine this issue, we are studying the interactions among

Received May 12, 2004; revised July 2, 2004; accepted July 3, 2004.

This work was supported by National Institute of Neurological Disorders and Strokes Grant NS29436 (M.P.N.) and United States-Israel Binational Science Foundation Grant 97-0074 (Y.M., M.P.N.). We thank Nicholas DeLong for assistance with figure preparation.

Correspondence should be addressed to Dr. Michael P. Nusbaum, Department of Neuroscience, University of Pennsylvania School of Medicine, 215 Stemmler Hall, Philadelphia, PA 19104-6074. E-mail: nusbaum@mail.med.upenn.edu. DOI:10.1523/JNEUROSCI.1840-04.2004

Copyright $\odot 2004$ Society for Neuroscience $\quad 0270-6474 / 04 / 247455-09 \$ 15.00 / 0$ an identified modulatory projection neuron and two rhythmically active motor circuits in the stomatogastric nervous system (STNS) of the crab Cancer borealis (Nusbaum and Beenhakker, 2002). The STNS contains four ganglia, including the paired commissural ganglia (CoGs), the unpaired oesophageal ganglion (OG) and stomatogastric ganglion (STG). Overlapping sets of STG neurons comprise the rhythmically active gastric mill (chewing) and pyloric (filtering of chewed food) circuits (Weimann et al., 1991; Weimann and Marder, 1994). Projection neurons originating in the CoGs and OG innervate the STG and modulate the gastric mill and pyloric rhythms (Nusbaum et al., 2001). Each of these projection neurons effectively influences the STG circuits when stimulated tonically, but most of them normally exhibit rhythmic activity that is time-locked to these circuits (Robertson and Moulins, 1984; Coleman and Nusbaum, 1994; Nagy et al., 1994; Norris et al., 1994, 1996).

One well described CoG projection neuron is modulatory commissural neuron 1 (MCN1) (Blitz et al., 1999). Tonic stimulation of MCN1 elicits the gastric mill rhythm and modulates the pyloric rhythm. However, spontaneous MCN1 activity is pyloric rhythm-timed as a result of inhibitory input that it receives within the $\mathrm{CoG}$ from the anterior burster $(\mathrm{AB})$ neuron, a pyloric pacemaker neuron (Coleman and Nusbaum, 1994). When this feedback pathway is eliminated and MCN1 is stimulated tonically 
to activate the gastric mill rhythm, the pyloric circuit continues to regulate gastric mill rhythm activity via a direct synapse from the $\mathrm{AB}$ neuron onto a gastric mill circuit neuron (Nadim et al., 1998; Bartos et al., 1999).

In this paper, we tested the hypothesis that the pyloric-timed activity of MCN1 provides a second pathway by which the pyloric circuit regulates and coordinates the gastric mill rhythm. We demonstrate that this indeed is the case. Moreover, this pathway alone is sufficient to enable pyloric regulation of the gastric mill rhythm, although both pyloric circuit pathways to the gastric mill circuit are necessary to replicate the naturally occurring rhythm. Thus, one role for rhythmic activity in a modulatory projection neuron is to enable one neuronal circuit to regulate the activity of a distinct but related neuronal circuit.

Parts of this paper have been published previously in abstract form (Wood and Nusbaum, 2001).

\section{Materials and Methods}

Animals. Adult male C. borealis were obtained from Commercial Lobster and Seafood Co. (Boston, MA) and the Marine Biological Laboratory (Woods Hole, MA). Crabs were maintained in artificial, aerated seawater $\left(10-12^{\circ} \mathrm{C}\right)$ until used. Animals were anesthetized with ice for $20-40 \mathrm{~min}$ before dissection. The dissection of the STNS was done in C. borealis physiological saline, containing (in $\mathrm{mm}$ ): $440 \mathrm{NaCl}, 26 \mathrm{MgCl}_{2}, 13 \mathrm{CaCl}_{2}$, $11 \mathrm{KCl}, 10$ Trisma base, and 5 maleic acid, $\mathrm{pH}$ 7.4-7.6. Dissections were performed in chilled saline as described previously (Blitz and Nusbaum, 1997). Experiments were performed using the isolated STNS (see Fig. 1A).

Electrophysiology. Electrophysiology was performed using standard methods as described previously (Beenhakker et al., 2004). The STNS was pinned down in a silicone elastomer-lined (Sylgard 184; K. R. Anderson, Santa Clara, CA) Petri dish. The isolated nervous system was superfused continuously $(7-12 \mathrm{ml} / \mathrm{min})$ with chilled physiological saline $\left(10-12^{\circ} \mathrm{C}\right)$. To facilitate intracellular recordings, the STG was desheathed and visualized with white light transmitted through a dark-field condenser (Nikon, Tokyo, Japan). Microelectrodes (15-30 M $\Omega$ ) were filled with $4 \mathrm{M}$ potassium acetate plus $20 \mathrm{~mm} \mathrm{KCl}$. Intracellular current injections were accomplished using Axoclamp 2B amplifiers in single-electrode discontinuous current clamp (DCC) mode (Axon Instruments, Foster City, CA). Sample rates in DCC mode ranged from 2.5 to $3 \mathrm{kHz}$.

Identification of STG neurons was done by documenting their activity patterns, synaptic interactions, and axonal projection paths as described previously (Weimann et al., 1991; Bartos and Nusbaum, 1997; Blitz and Nusbaum, 1997). Identification of MCN1 was accomplished via its axon location (Coleman and Nusbaum, 1994; Bartos and Nusbaum, 1997) and interactions in the STG (Blitz et al., 1999; Beenhakker and Nusbaum, 2004). Selective activation of MCN1 was achieved by stimulating the inferior oesophageal nerves (ions) (each ion, 10-25 Hz) (Bartos and Nusbaum, 1997). The selective activation of MCN1 via ion stimulation was assured by the fact that the axon of only one other STG-projecting CoG neuron, modulatory commissural neuron 5 (MCN5), is present in the ion, and MCN1 has a lower activation threshold than MCN5 during ion stimulation (Coleman et al., 1992; Norris et al., 1996; Bartos and Nusbaum, 1997). In some preparations, modulatory influence in the STG from projection neurons in the CoG was eliminated by transecting both ions and superior oesophageal nerves (sons) (see Fig. $1 A$ ). Under these conditions, the pyloric rhythm either stops or slows $(0.2-0.8 \mathrm{~Hz})$ from a cycle frequency that is typically $>1 \mathrm{~Hz}$. When the gastric mill rhythm was active before the ions and sons were transected, the rhythm terminated as soon as these nerves were cut.

Experimental control of a pyloric rhythm-timed activity pattern in MCN1 was accomplished by extracellular stimulation of the ion(s) between each set of successive bursts of the paired pyloric dilator (PD) neurons. This protocol involved triggering each ion stimulation from the start of a PD neuron burst with an added delay that included the entire PD burst and a duration that included the period between PD bursts. The $\mathrm{PD}$ neurons, along with the $\mathrm{AB}$ neuron to which they are electrically coupled, are members of the pyloric pacemaker group (see Fig. $1 B$ ). The cycle frequency of the pyloric rhythm is determined primarily by this set of neurons (Hooper and Marder, 1987). Intracellular recording of the PD neuron was used to monitor the relevant parameters of the pyloric rhythm.

Detection of PD neuron activity and control of MCN1 stimulation was done using either a National Instruments (Austin, TX) analog-to-digital (A/D) board (AT-MI0-16E2) and interface with Lab Windows CVI (F.N. and Y.M.) or a Cambridge Electronic Design (Cambridge, UK) $1401 \mathrm{~A} / \mathrm{D}$ board with interface, including custom scripts (D.E.W.) for Spike 2 data acquisition software (version 4.0; Cambridge Electronic Design). In all stimulation experiments, MCN1 activity was controlled directly by the stimulation protocol because each extracellular stimulation pulse (duration, $1 \mathrm{msec}$ ) elicits a single action potential from $\mathrm{MCN} 1$ (Bartos and Nusbaum, 1997). For experiments in which the pyloric rhythm was suppressed, the timing of the rhythmic activation of MCN1 was controlled directly from a stimulator (Grass model S-88; Astromed, West Warwick, RI).

Data analysis. Data were recorded using a chart recorder (Astromed MT-95000) and digitized via Spike 2 data acquisition software to a computer. Data analyses were conducted either manually or on digitized data using a custom-written Spike 2 program called "The Crab Analyzer" (freely available at http://www.neurobiologie.de/) to determine the activity levels and phase relationships of neurons. The pyloric cycle period was defined as the interval between the onset of an impulse burst in the PD neuron and the onset of the subsequent PD neuron burst. Pyloric cycle frequency was determined as the reciprocal of the pyloric cycle period. In each experiment, a sequence of 20 pyloric cycles was used to determine the mean pyloric cycle frequency.

There are eight types of gastric mill circuit neurons, most of which occur as single copies (Harris-Warrick et al., 1992; Blitz and Nusbaum, 1997). The core of the gastric mill rhythm generator includes reciprocal inhibition between interneuron 1 (Int1) and the lateral gastric (LG) neuron (see Fig. 1 B) (Coleman et al., 1995; Bartos et al., 1999). In this paper, gastric mill rhythms were monitored by recording the activity of the LG neuron and the dorsal gastric (DG) neuron. The gastric mill rhythmtimed DG neuron bursts are coactive with those of Int1, and they alternate with the LG neuron bursts (see Fig. 2). The LG neuron was recorded intracellularly, whereas the DG neuron was recorded extracellularly from the dorsal gastric nerve (dgn) (see Figs. 1A, 2).

The gastric mill cycle period was defined as the interval between the onset of consecutive LG neuron bursts. Ten consecutive gastric mill cycles were used for computing the mean number of action potentials per pyloric-timed LG neuron burst, the mean LG neuron duty cycle (fraction of a gastric mill cycle during which the LG neuron was active), and the mean value for the gastric mill cycle period. When the LG neuron bursts were subdivided by pyloric-timed input during the gastric mill rhythm, its gastric mill-timed burst was defined as the duration from the onset of LG neuron activity until the next episode of Int1-mediated inhibition. This typically spanned several pyloric-timed LG neuron bursts. The hyperpolarization resulting from the Int1-mediated inhibition was typically discernable (more hyperpolarized) from that resulting from the pyloric-timed removal of the MCN1-mediated excitation that subdivided each LG neuron burst (see Fig. 2A). Barrages of unitary IPSPs from Int1 were also evident during Int1-mediated inhibition. The occasional action potential that occurred during the LG neuron interburst was not included as part of its burst. Coordination between the gastric mill and pyloric rhythms was computed as the latency from the onset of the PD neuron burst that immediately preceded each LG neuron burst to the start of that LG neuron burst (Nadim et al., 1998; Bartos et al., 1999). In some cases, the pyloric-gastric mill relationship was measured as the latency from the onset of an MCN1 burst that immediately preceded an LG neuron burst to the onset of that LG neuron burst.

Figures were prepared by scanning sequences of recordings using a Hewlett-Packard (Palo Alto, CA) Scanjet IIc with Deskscan II (version 2.0a) software or from digitized records. Final figures were prepared with CorelDraw (version 9.0 for Windows) or Microsoft Powerpoint 2002 (Microsoft, Seattle, WA). Graphics and statistics were generated using Sigma Plot 4.0 and Sigma Stat 2.03 (SPSS, Chicago, IL). Statistical tests used to analyze data were one-way ANOVA, repeated-measures 


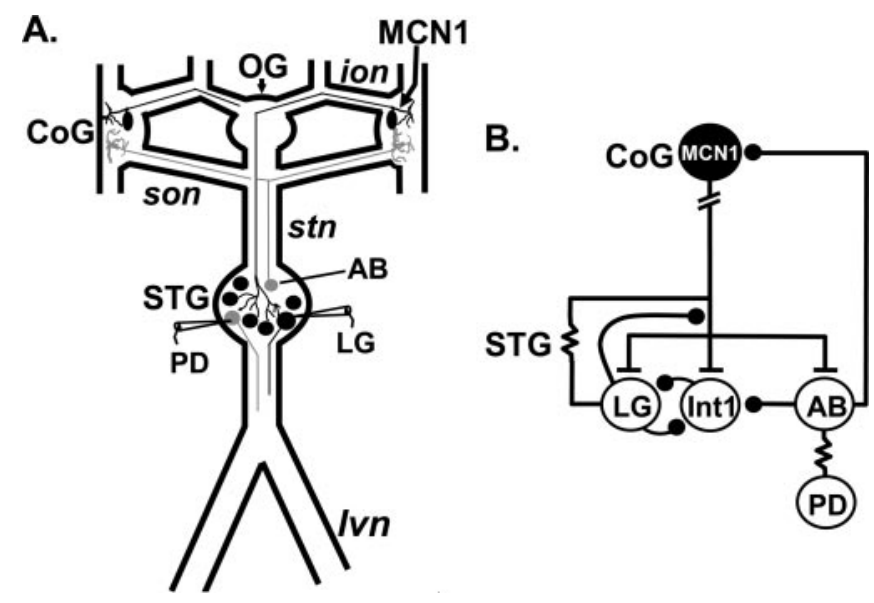

Figure 1. Schematic of the isolated STNS and a circuit diagram of the synaptic relationships between the projection neuron MCN1 and the primary gastric mill and pyloric circuit pattern generator neurons. $A$, The STNS includes four ganglia plus their connecting and peripheral nerves. The ganglia are the STG, $O G$, and the CoGs. The axonal projection pattern of only one MCN1 is shown. $B$, Circuit schematic illustrating the relevant connections between MCN1 and the gastric mill and pyloric pattern generator neurons (Coleman and Nusbaum, 1994; Coleman et al., 1995; Bartos et al., 1999). The reciprocally inhibitory LG neuron and Int 1 form the core of the gastric mill pattern generator. The two pathways by which the pyloric circuit can influence the gastric mill circuit are the inhibitory synapses from the pyloric pacemaker neuron $A B$ to MCN1 in the $\mathrm{COG}_{\text {and }}$ Int 1 in the STG. Ivn, Lateral ventricular nerve; stn, stomatogastric nerve; filled circle, synaptic inhibition; t-bar, synaptic excitation; resistor, electrical coupling.

ANOVA, and Friedman repeated-measures ANOVA on ranks (with Tukey's test for multiple comparisons). Comparisons for equal variance were done with Levene's median test for equal variance. Data are presented as means $\pm \mathrm{SD}$.

\section{Results}

MCN1 activity is pyloric-timed during spontaneous gastric mill rhythms

In the isolated C. borealis STNS, as well as in vivo, the pyloric and gastric mill rhythms both require modulatory input from projection neurons in the CoGs (Fig. 1A). However, the projection neurons responsible for activating the gastric mill rhythm generally are not spontaneously active (Coleman and Nusbaum, 1994; Blitz et al., 1999; Nusbaum and Beenhakker, 2002). Activation of one of these latter projection neurons, MCN1, initiates the gastric mill rhythm and modulates the pyloric rhythm (Blitz et al., 1999). In the isolated STNS, all spontaneously active gastric mill rhythms that we recorded were associated with relatively strong, spontaneous activity in MCN1. MCN1 activity was readily recorded extracellularly in the ions (Fig. 2A) (Coleman and Nusbaum, 1994). These rhythms exhibited one of two gastric mill patterns, including the one comparable with the rhythm driven by coactivity in MCN1 and a second projection neuron called commissural projection neuron 2 (CPN2) (Beenhakker and Nusbaum, 2004) and the one driven solely by MCN1 activity (see below). The MCN1-CPN2-like rhythms often terminated after ion transection, although in some cases the rhythm persisted in an altered form that was comparable with the one driven by rhythmic bursting in CPN2 alone (Beenhakker and Nusbaum, 2004). In all cases in which the spontaneous gastric mill rhythm exhibited the pattern ascribed below to being driven solely by MCN1, the rhythm terminated after ion transection.

\section{Spontaneous gastric mill rhythms differ from those elicited by tonic MCN1 activity}

During spontaneously active gastric mill rhythms, MCN1 activity was commonly rhythmic. Whenever the gastric mill rhythm was driven by MCN1 alone, the rhythmic activity pattern in MCN1 was entirely pyloric-timed ( $n=22$ of 22 preparations) (Fig. $2 A$ ). The gastric mill rhythm (cycle frequency range, $0.05-0.2 \mathrm{~Hz}$ ) is considerably slower than the pyloric rhythm (cycle frequency during the gastric mill rhythm, $\sim 1.0 \mathrm{~Hz}$ ) (Bartos and Nusbaum, 1997), so there are always several pyloric cycles per gastric mill cycle (Fig. 2). In contrast to the MCN1 activity pattern during the above-mentioned gastric mill rhythm, during the MCN1-CPN2elicited gastric mill rhythm, MCN1 activity is only pyloric-timed during the half of each cycle when Intl and the DG neuron are active, whereas MCN1 is tonically active during each LG neuron burst (Beenhakker and Nusbaum, 2004). During its pylorictimed pattern, MCN1 activity was terminated during each burst of the pyloric pacemaker neurons ( $\mathrm{AB}$ and $\mathrm{PD}$ neurons). This pyloric-timed pattern results from an inhibitory synapse onto MCN1 from the AB neuron (Coleman and Nusbaum, 1994). The $\mathrm{AB}$ neuron projects to the CoGs via the stomatogastric nerve and sons (Fig. 1A). The PD neurons do not project to the CoGs but instead project through the lateral ventricular nerves (Fig. $1 A$ ) to innervate pyloric dilator muscle fibers (Hooper et al., 1986).

During the spontaneously active gastric mill rhythms that were accompanied by persistent pyloric-timed MCN1 activity, either one or both MCN1s were active. At these times, the MCN1 firing frequency within each pyloric-timed burst ranged from 15 to $28 \mathrm{~Hz}$ (mean MCN1 firing frequency, $22.3 \pm 3.7 \mathrm{~Hz} ; n=13$ ), although its intraburst firing frequency was stable in any one preparation. This MCN1 activity extended for $\sim 80 \%$ (79 $\pm 9 \%$; $n=13$ ) of each pyloric cycle.

It was readily apparent that the gastric mill rhythm that occurred when MCN1 was pyloric-timed was different from the one occurring during the previously characterized tonic MCN1 stimulation (Fig. 2) (Coleman and Nusbaum, 1994; Coleman et al., 1995; Bartos et al., 1999). Therefore, we aimed to understand how the pyloric timing in the MCN1 activity pattern altered the gastric mill rhythm. We then aimed to determine what aspects of this altered rhythm required the pyloric-timed $\mathrm{MCN} 1$ activity to be time-locked to the pyloric pacemaker bursts (Bartos et al., 1999). Because there were obvious changes in the gastric mill rhythm, but not in the pyloric rhythm, between times when MCN1 activity was tonic and pyloric-timed, we focused on comparing the gastric mill rhythms elicited by tonic and rhythmic MCN1 activity. We used levels of MCN1 stimulation $(25 \mathrm{~Hz})$ that were within the normal range of the intraburst firing frequency of MCN1 when its spontaneous activity was pyloric-timed. To assess the state of the gastric mill rhythm, we focused primarily on the activity of the gastric mill rhythm generator neuron LG.

There were several qualitative differences between the spontaneously active gastric mill rhythms and those elicited by tonic stimulation of MCN1. One such difference was that the LG neuron burst pattern was divided into pyloric-timed bursts in the former condition, whereas it was tonic in the latter condition (Figs. 2, 3). A second qualitative difference between the gastric mill rhythms elicited by pyloric-timed and tonic MCN1 activity was in the pattern of the LG neuron membrane potential oscillations that occurred during each LG neuron interburst. In both cases, these subthreshold oscillations were pyloric-timed, and in both instances, the depolarizing aspect of these oscillations initiated during the $\mathrm{AB}-\mathrm{PD}$ neuron burst (Figs. 2, 3). This timing resulted from the fact that the onset of each rhythmic depolarization represented the periodic removal of Int 1 inhibition of the LG neuron. This disinhibition is a consequence of $\mathrm{AB}$ neuron inhibition of Int1 (Fig. $1 B$ ), and one of these rhythmic events triggers the LG neuron burst onset during each cycle of the gastric mill 
rhythm elicited by tonic MCN1 stimulation (Bartos et al., 1999). At such times, these disinhibitions help regulate both the gastric mill cycle frequency and the coordination between the gastric mill and pyloric rhythms (Bartos et al., 1999). When MCN1 was stimulated tonically, these rhythmic depolarizations were smooth, single-step events because under this condition, the AB-mediated inhibition of Int 1 was the only pyloric-timed depolarizing event occurring in the LG neuron (Bartos et al., 1999). However, when MCN1 activity was pyloric-timed, its excitation of the LG neuron was comparably rhythmic, thereby providing a second pyloric-timed depolarizing event to the LG neuron (Fig. $3 B)$. MCN1 provides both electrical and modulatory excitation to the LG neuron (Coleman et al., 1995; Wood et al., 2000). The relative timing of the rhythmic MCN1-mediated excitation of the LG neuron was such that during the LG neuron interburst, each excitatory episode initiated during or just after the peak of the associated disinhibition (Fig. 3, arrows). Note that the duration of the rhythmic MCN1-mediated excitation was abbreviated by the Int1-mediated inhibition of the LG neuron that began soon after each MCN1 burst onset.

There was also a qualitative difference in the event that triggered LG neuron burst initiation when MCN1 activity was tonic and pyloric-timed. When MCN1 was tonically active, the start of every LG neuron burst occurred during a disinhibition event (Nadim et al., 1998; Bartos et al., 1999). In contrast, during rhythmic MCN1 activity, the onset of most LG neuron bursts occurred during an episode of MCN1-mediated excitation in LG (Fig. 3). In fact, during spontaneous gastric mill rhythms, the LG neuron burst initiated during an episode of MCN1-mediated excitation in $75 \%$ of the gastric mill cycles (113 of 150 cycles; $n=5$ ).

Comparable gastric mill rhythms resulted from pyloric-timed MCN1 stimulation and spontaneous MCN1 activity

There were additional, quantitative changes in the gastric mill rhythm when MCN1 activity was pyloric-timed instead of tonic. However, it was not practical to use spontaneously occurring gastric mill rhythms to document these changes because these rhythms occurred too infrequently. Thus, to more reliably obtain gastric mill rhythms driven by pyloric-timed MCN1 activity and to have better experimental control, we developed a protocol in which we replaced the $A B$ neuron inhibition of MCN1 with a computer-controlled, pyloric-timed rhythmic stimulation of MCN1 (see Materials and Methods) (Fig. 3A). As shown in Figure 3 , in which this manipulation was performed in preparations where the CoGs remained connected to the STG, the gastric mill rhythm generated by this stimulation protocol was comparable with the one that occurred during spontaneous gastric mill
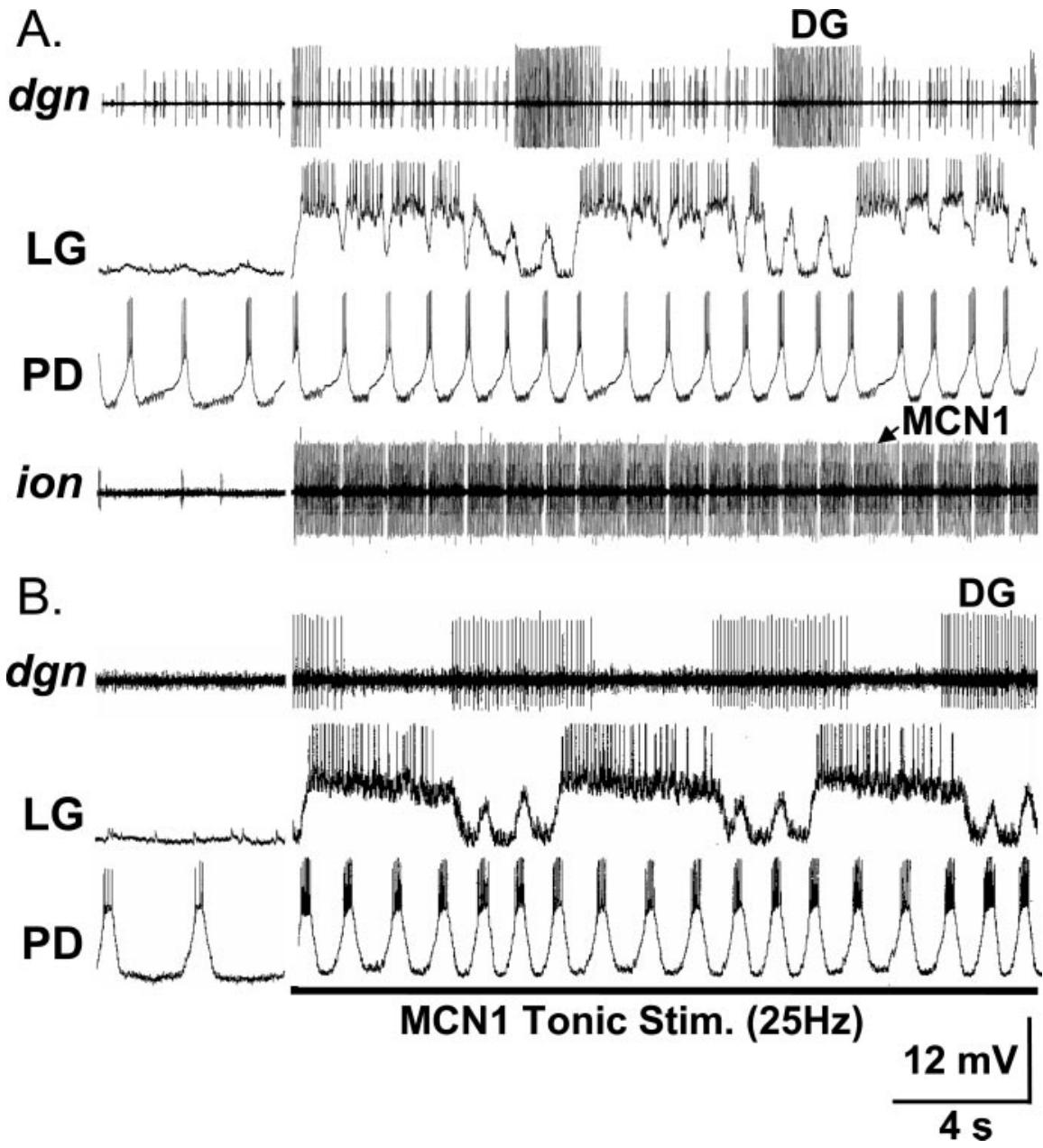

Figure 2. Pyloric-timed and tonic activity in the modulatory projection neuron MCN1 elicit distinct gastric mill rhythms in the isolated stomatogastric nervous system. A, Left, When MCN1 (arrow, ion) was not active, there was no gastric mill rhythm (LG, dgn) and a relatively slow pyloric rhythm (PD). Right, Spontaneous, pyloric-timed bursting of MCN1 elicited the gastric mill rhythm was inactive during each PD neuron burst and that each gastric mill-timed $L G$ neuron burst was composed of a set of pyloric-timed . gastric mill rhythm and strengthened the pyloric rhythm. During tonic MCN1 stimulation, each LG neuron burst was tonic instead of pyloric-timed. Most hyperpolarized membrane potential: $L G,-70 \mathrm{mV}$; PD, $-54 \mathrm{mV}$.

rhythms. This included the presence of pyloric-timed LG neuron bursts and two-step, pyloric-timed depolarizations during each LG neuron interburst (Fig. 3). Note that, as described above for the spontaneous condition, the MCN1-mediated depolarizations during the LG neuron interburst were abbreviated by the presence of the rhythmic inhibitory input arriving in the LG neuron from Int1 soon after the start of each MCN1 burst (Fig. 3C).

There were two quantitative differences between the gastric mill rhythms that occurred when MCN1 activity was pylorictimed and tonic. The first difference was that the gastric mill rhythm was significantly faster when MCN1 activity was tonic (tonic, $0.14 \pm 0.04 \mathrm{~Hz}$; spontaneous pyloric-timed, $0.12 \pm 0.02$ $\mathrm{Hz} ; n=12 ; p<0.02)$. In contrast, there was no difference in the speed of this gastric mill rhythm between times when the rhythm was spontaneous and when it was evoked by pyloric-timed MCN1 stimulation (pyloric-timed stimulation, $0.12 \pm 0.03 \mathrm{~Hz}$; $n=12 ; p>0.05)$.

We also found that the temporal relationship between the pyloric and gastric mill rhythms was changed when MCN1 activ- 
A.

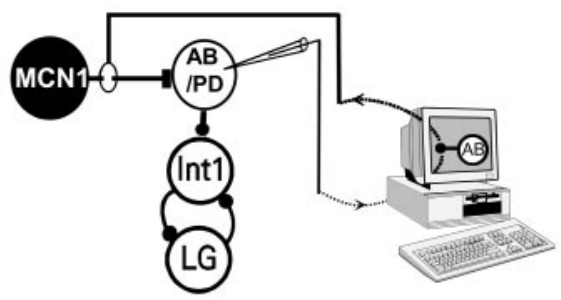

B.

ion

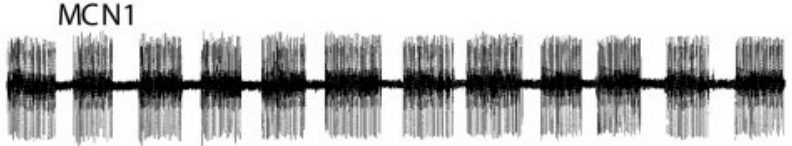

LG

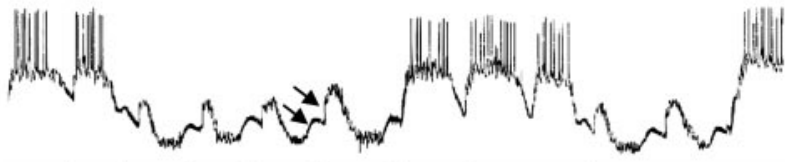

PD

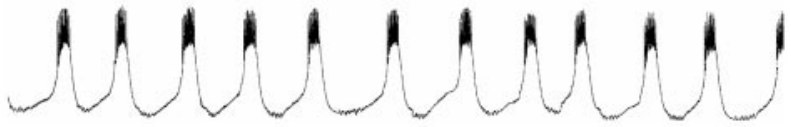

C.

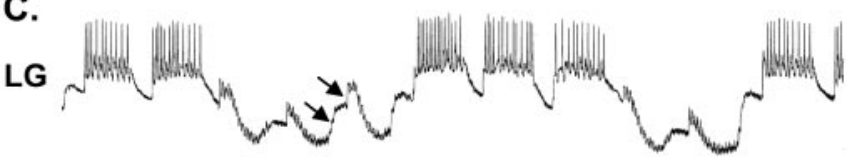

PD

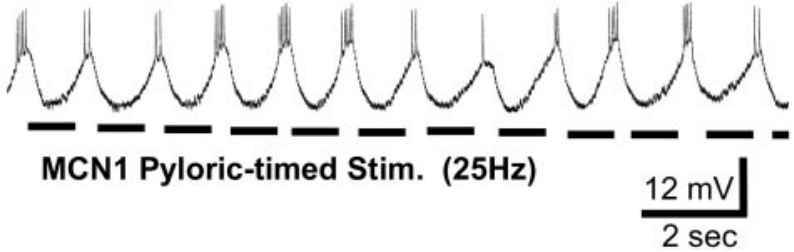

Figure 3. Spontaneous and experimentally elicited rhythmic (pyloric-timed) activity in MCN1 elicits comparable gastric mill rhythms. $A$, Schematic representation of experiments in which MCN1 was rhythmically activated during the interburst of the pyloric pacemaker neurons (AB-PD). The onset of each pyloric cycle was used with an added delay to trigger the output of a stimulator to stimulate the ion ( $s$ ) and thereby evoke a pyloric-timed activation of MCN1 that alternated with that of the AB and PD neurons (see Materials and Methods). B, Spontaneous MCN1 activity elicited the gastric mill rhythm. Note that MCN1 was inactive during each PD neuron burst and that the $L G$ neuron bursts were pyloric-timed (coactive with MCN1). Also note that during each $L G$ neuron interburst there were two consecutive subthreshold depolarizations in $\mathrm{LG}$ during each pyloric cycle (arrows). Most hyperpolarized membrane potential: $\mathrm{LG},-62$ $\mathrm{mV}$; PD, $-55 \mathrm{mV}$. C, Pyloric-timed stimulation (Stim.) of MCN1 (intraburst frequency, $25 \mathrm{~Hz}$ ) elicited a gastric mill rhythm comparable with the rhythm elicited by spontaneous MCN1 activity in $B$. Note the pyloric-timed bursting of the $L G$ neuron and the two consecutive depolarizations per pyloric cycle in $L G$ during each $L G$ neuron interburst (arrows). Most hyperpolarized membrane potential: $\mathrm{LG},-68 \mathrm{mV} ; \mathrm{PD},-57 \mathrm{mV}$.

ity was changed from tonic to rhythmic. Our previous work showed that during tonic $\mathrm{MCN} 1$ stimulation at $10 \mathrm{~Hz}$, there is a constant latency relationship between the onset of each LG neuron burst and the immediately preceding PD neuron burst (Nadim et al., 1998; Bartos et al., 1999). This latency value was unchanged when MCN1 was activated tonically at 25 instead of $10 \mathrm{~Hz}(p>0.05 ; n=12)$ (data not shown). A consistent latency relationship was also maintained when MCN1 was rhythmically activated at an intraburst frequency of $25 \mathrm{~Hz}$ with an $80 \%$ duty cycle (PD to LG latency, $323 \pm 40 \mathrm{msec} ; n=12$ ) and during spontaneous MCN1-elicited gastric mill rhythms $(362 \pm 62.9$ msec; $n=13$ ). The latency value was not different for these latter two conditions when MCN1 activity was pyloric-timed $(p>$ $0.05)$. However, both the mean latency and its variability were decreased when MCN1 was tonically active relative to times when MCN1 activity was pyloric-timed, whether attributable to spontaneous activity or rhythmic MCN1 stimulation $(312 \pm 10 \mathrm{msec}$; $p<0.01 ; n=13)$. There was also a comparable latency from the onset of the immediately preceding MCN1 burst to LG neuron burst onset during spontaneous and rhythmically stimulated MCN1 activity $(n=11 ; p>0.05)$. It was not surprising that the mean latency value was lower when determined from MCN1 burst onset $(141.7 \pm 53.7 \mathrm{msec} ; n=12 ; p<0.01)$ than from PD neuron burst onset because, as indicated above for the spontaneous rhythms, when MCN1 activity was pyloric-timed, the LG neuron burst was more likely to initiate during an episode of MCN1-mediated excitation. The same was true during rhythmic MCN1 stimulations ( 139 of 150 cycles; $93 \% ; n=5$ preparations).

After determining that the spontaneous MCN1-elicited gastric mill rhythm was well mimicked by pyloric-timed MCN1 stimulation, we used this stimulation protocol to determine whether the pyloric timing of the MCN1 activity pattern contributed to the previously documented pyloric regulation of the speed of the MCN1-elicited gastric mill rhythm (Bartos et al., 1999). As indicated above, Bartos et al. (1999) showed that when MCN1 was stimulated tonically in the isolated STG, the pyloric rhythm regulated the speed of the gastric mill rhythm via $A B$ neuron inhibition of Int1. Thus, under these conditions, the gastric mill rhythm was slowed significantly whenever the pyloric rhythm was experimentally slowed or terminated (Fig. 4A,C) (Bartos et al., 1999). The speed of the pyloric rhythm is readily controlled by injecting current into the $\mathrm{PD}$ and/or $\mathrm{AB}$ neurons. In contrast to the slowing of the gastric mill rhythm that occurred when the pyloric rhythm was suppressed during tonic MCN1 activity, suppressing the pyloric rhythm while MCN1 was stimulated in a pyloric pattern resulted in no change in the gastric mill cycle frequency (Fig. $4 B, C$ ). As is evident from the intracellular recording of the LG neuron in Figure $4 B$, under this condition the rhythmic excitation of the LG neuron by MCN1 enabled LG to still exhibit pyloric-timed membrane potential oscillations when the pyloric rhythm was suppressed. At times when the pyloric rhythm was suppressed but MCN1 activity retained a pyloric-like pattern, the onset of every LG burst occurred during an episode of MCN1 activity (Fig. 4B). There was, however, an increase in the mean latency from MCN1 burst onset to LG burst onset from when the pyloric rhythm was present $(141.7 \pm 53.7$ $\operatorname{msec} ; n=12)$ to when it was suppressed ( $240 \pm 196 \mathrm{msec} ; n=12$; $p<0.001)$. Nonetheless, the pyloric-timed excitation from MCN1 to the LG neuron was sufficient to maintain the speed of the gastric mill rhythm.

The presence of pyloric timing in MCN1 also altered the pattern of the gastric mill rhythm. We assessed this influence on the gastric mill pattern by comparing the LG neuron duty cycle during rhythms elicited by both tonic and rhythmic MCN1 activity. We also determined whether the pyloric-timed activity of MCN1 alone was sufficient to maintain the normal LG neuron duty cycle by rhythmically stimulating $\mathrm{MCN} 1$ while suppressing the pyloric rhythm.

Neither source of pyloric input to the gastric mill circuit, when present by itself, was sufficient to mimic the natural condition of having both pyloric pathways present (Fig. 5). Thus, relative to having both pyloric pathways present, the LG neuron burst occupied a smaller fraction of each cycle when the only source of pyloric influence was the indirect pathway ( $\mathrm{AB}$ neuron inhibition of MCN1, $p<0.01 ; n=12$ ), whereas it occupied a larger fraction of each gastric mill cycle when the only available pyloric pathway was the direct one ( $\mathrm{AB}$ neuron inhibition of Int $1, p<0.05 ; n=$ 
12) (Fig. 5). LG neuron duty cycle was most reduced when there was no source of pyloric input to the gastric mill circuit (MCN1 tonically active, pyloric rhythm suppressed, $p<0.01 ; n=12$ ) (Fig. 5).

\section{Consequences of the coordination between the pyloric and gastric mill rhythms}

We next aimed to determine whether the differences between gastric mill rhythms elicited by tonic and pyloric-timed MCN1 activity required the presence of the latency locking between the activity of MCN1 and the pyloric pacemaker neurons. Therefore, we compared the gastric mill rhythm elicited by pyloric-related activity patterns in MCN1 that were latency locked to the preceding PD neuron burst (the natural condition) with those in which the rhythmic MCN1 activity was free-running with respect to the pyloric rhythm (Fig. 6). In the free-running condition, we unlinked the pyloric-related activity of MCN1 from PD neuron activity but retained all other stimulation parameters, including those for MCN1 burst cycle frequency $(1 \mathrm{~Hz})$, intraburst firing frequency $(25 \mathrm{~Hz})$, and burst duration (800 $\mathrm{msec}$ ). We focused our comparison on the gastric mill cycle frequency, the pyloric to gastric mill latency relationship, LG neuron duty cycle, and the waveform pattern in the LG neuron during its interburst. As elaborated below, unlinking the MCN1 activity pattern from the pyloric rhythm changed some of these parameters.

Some aspects of the gastric mill rhythm were unaffected by unlinking rhythmic MCN1 activity from the pyloric rhythm. For example, the speed of the gastric mill rhythm was the same whether rhythmic MCN1 activity was linked to the pyloric rhythm $(p>0.05 ; n=12)$ (Fig. 6B1). The LG neuron duty cycle was also unaffected by changing the relationship between MCN1 activity and the pyloric rhythm (Fig. 6B2).

Several other aspects of the gastric mill rhythm were altered by unlinking rhythmic MCN1 activity from the pyloric rhythm. One example of such a change was in the LG neuron waveform during its interburst. As described above, when MCN1 activity was pyloric-linked, the LG neuron interburst usually consisted of a repeating set of three pyloric-timed events, including two consecutive depolarizing steps followed by an IPSP-associated hyperpolarization (Fig. 3). The first depolarizing step (AB-mediated removal of Int1 inhibition of LG) and the hyperpolarization (pyloric-timed Int1 inhibition of LG) are direct pyloric circuitmediated synaptic events (Bartos et al., 1999). The second of the two depolarizing steps resulted from MCN1 excitation of the LG neuron. When MCN1 activity was unlinked from the pyloric rhythm, the occurrence of the MCN1 excitation of the LG neuron was similarly unlinked from the first depolarizing step and the subsequent hyperpolarization. Consequently, in the unlinked condition, the excitatory input from MCN1 to the LG neuron had a continually changing relationship with the direct pyloric circuit inputs to the LG neuron, resulting in an altered LG neuron waveform during each interburst (Fig. 6A).

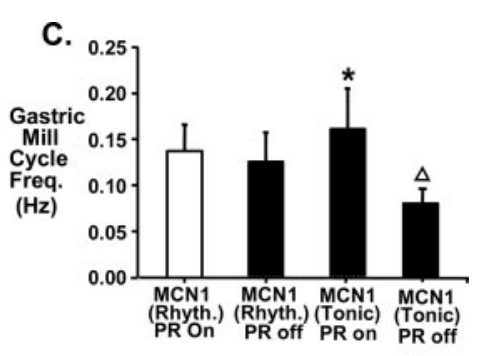

MCN1 Tonic Stim. $(25 \mathrm{~Hz})$
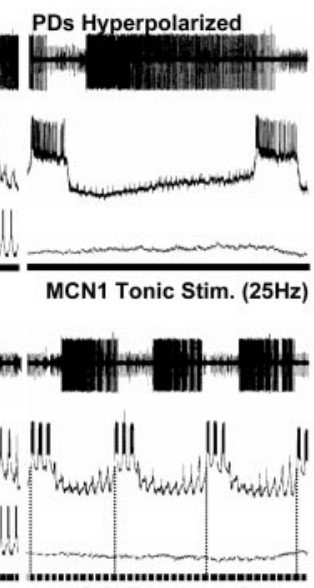

MCN1 Rhythmic Stim.

$$
\frac{10 \mathrm{mV}}{9 \mathrm{~s}}
$$




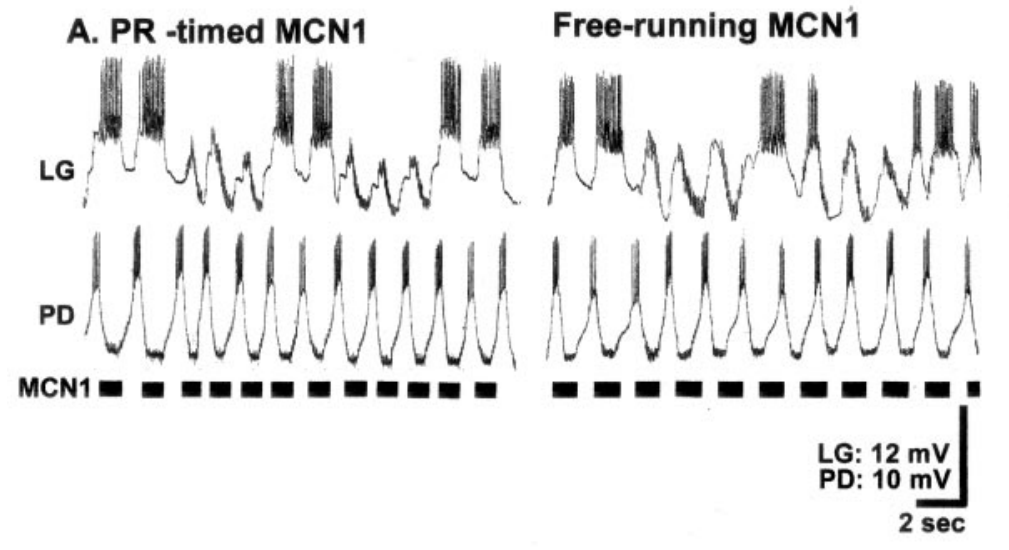

B1.

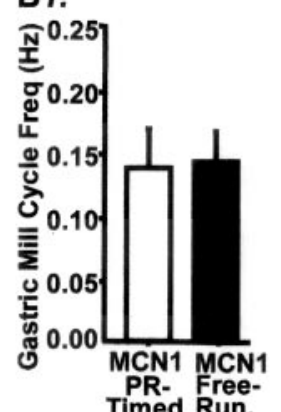

B3.

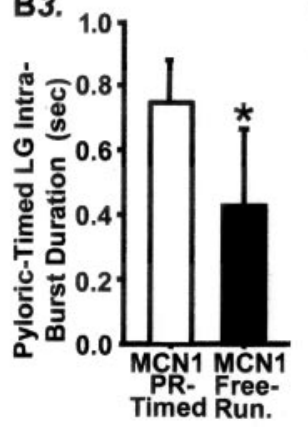

B2. LG Neuron Duty Cycle

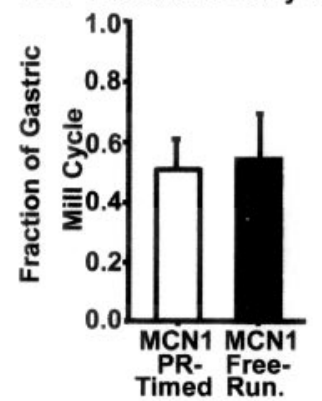

C.

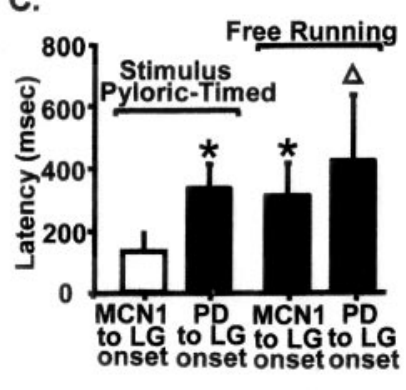

Figure 6. Pyloric rhythm regulation of MCN1 activity is necessary for normal LG neuron burst structure and gastric mill-pyloric coordination. A, Left, MCN1 stimulation was pyloric-timed (stimulus bars) (see Materials and Methods), eliciting the standard gastric mill rhythm as indicated by the regular duration of the pyloric-timed LG neuron bursts that combine to constitute each gastric mill-timed burst of $L G$. Note that the pyloric-timed $L G$ bursts were separated by smaller-amplitude hyperpolarizations than were each gastric mill-timed $L G$ neuron burst. The latter bursts were also separated by several pyloric-timed subthreshold depolarizations. Right, MCN1 was stimulated using the same pyloric-related parameters except that MCN1 activity was free-running relative to the pyloric rhythm (stimulus bars). Note the variability in the duration of the pyloric-timed LG neuron bursts. $B$, Consequences of unlinking MCN1 activity from the pyloric rhythm. $B 1$, Gastric mill cycle frequency and the gastric mill-related duty cycle (B2) of $\mathrm{LG}$ were unchanged when MCN1 activity was switched from pyloric-timed to free-running $(p>0.05 ; n=12) . B 3$, There was a reduction in the mean duration of each pyloric-timed LG neuron burst when MCN1 activity was switched from pyloric-timed to free-running $(p<0.05 ; n=12)$. C, There was an increase in the mean latency from the onset of the pyloric cycle immediately preceding the $L G$ neuron burst to the onset of that $L G$ (gastric mill) burst when $M C N 1$ activity was free-running relative to the pyloric rhythm. This was the case whether the latency relationship was measured relative to the burst onset of the PD neuron or MCN1. ${ }^{*} p<0.05$ relative to all other conditions except those with the same symbol; ${ }^{\Delta} p<$ 0.01 relative to all other conditions; $n=20$ for all conditions.

linked condition ( $p<0.05 ; n=11)$ (Fig. 6B3), despite the fact that neither the mean gastric mill-related duty cycle of the LG neuron (Fig. 6B2) nor the mean gastric mill cycle period (Fig. $6 \mathrm{B1})$ was altered. Moreover, these pyloric-timed LG neuron burst durations were more variable in the unlinked condition relative to gastric mill rhythms elicited with pyloric-timed activation of MCN1 $(p<0.05 ; n=11)$ (Fig. 6B3).

Another consequence of unlinking MCN1 activity from the pyloric rhythm was an increase in the mean latency of the PD neuron burst onset relative to the onset of the LG neuron burst $(n=12 ; p<0.01)$ (Fig. $6 C)$. There was a concomitant increase in the variability of this latency relationship (Fig. $6 C$ ). This result suggested that the coordination of the two pyloric-timed inputs to the LG neuron was necessary for maintaining the normal coordination of the pyloric and gastric mill rhythms.

During gastric mill rhythms elicited by either spontaneous activity or pyloric-timed stimulation of MCN1, there was a shorter latency between MCN1 and LG neuron burst onsets than between PD neuron and LG neuron burst onsets (Fig. 6C). This relationship persisted in the free-running condition, but both of these latency measurements were larger than their counterpart measurements during pyloric-timed MCN1 activity $(n=12 ; p<$ 0.01 ) (Fig. 6C). Finally, as we showed previously, most LG neuron bursts initiated during an MCN1 burst when the gastric mill rhythm was elicited by either spontaneous MCN1 activity or pyloric-timed stimulations of MCN1. This relationship was not as strict when the pyloric and MCN1 activities were uncoordinated. During the free-running gastric mill rhythms, the LG neu- ron burst initiated during an episode of MCN1-mediated excitation in only $42 \%$ of the gastric mill cycles ( 63 of 150 cycles; $n=5$ ).

\section{Discussion}

We have shown that rhythmic synaptic feedback from a central pattern-generating circuit to a modulatory projection neuron can enable that circuit to regulate the activity of a distinct but related neuronal circuit. Specifically, we have demonstrated that the pyloric rhythm-timed activity of MCN1 enables the pyloric circuit to regulate several aspects of the gastric mill rhythm, including its speed, pattern, and coordination with the pyloric rhythm. The pyloric circuit also influences the gastric mill rhythm by a second pathway, within the STG, via an inhibitory synapse from the pyloric pacemaker $\mathrm{AB}$ neuron to the gastric mill pattern generator neuron Int1 (Bartos et al., 1999). As discussed below, these two pathways provide both complementary and distinct contributions to the pyloric regulation of the gastric mill rhythm.

Patterned synaptic feedback from central pattern-generating circuits to their modulatory inputs is well documented in many motor systems (Weeks, 1981; Robertson and Moulins, 1984; Nusbaum and Kristan, 1986; Dubuc and Grillner, 1989; Kasicki et al., 1989; Nagy et al., 1994; Frost and Katz, 1996; Perrins and Weiss, 1996; Deliagina et al., 2000). In the few previous studies that aimed to understand the function of this rhythmic feedback, the focus was generally restricted to potential consequences for the circuit responsible for this feedback (Weeks, 1981; Kasicki et al., 1989; Deliagina et al., 2000). The results of these studies were 
inconclusive. In the case of the leech swim system, several possible roles were eliminated because the rhythmicity of the swiminitiating cell 204 did not contribute to swim initiation, maintenance, or cycle phasing (Weeks, 1981). In the lamprey swim system, there are correlative data supporting the possibility that the swim-related rhythmic activity in reticulospinal neurons serves a gating function (Deliagina et al., 2000). In the present study, we did not examine whether the pyloric-timed activity in MCN1 had a different influence on the pyloric rhythm than did tonic MCN1 activity. However, this rhythmic MCN1 activity pattern clearly participated in the pyloric regulation of the gastric mill rhythm.

Intercircuit interactions underlie many complex behaviors. There are, for example, well documented interactions between the respiratory and locomotory systems (Cattaert and Clarac, 1983; Kawahara et al., 1989; Morin and Viala, 2002), between respiration and vocalization (Larson et al., 1994; Suthers, 1997), and between different aspects of feeding (Perrins and Weiss, 1996; Clemens et al., 1998). However, there is little information available regarding the cellular basis of how such interactions coordinate the relevant neuronal circuits. In the stomatogastric system, previous studies showed that the gastric mill circuit regulates the pyloric rhythm via LG neuron presynaptic inhibition of the transmitter-mediated actions of MCN1, but not its electrical synapses, within the STG (Coleman et al., 1995; Bartos and Nusbaum, 1997). Moreover, as mentioned above, the pyloric circuit regulates the gastric mill rhythm via $\mathrm{AB}$ neuron inhibition of Int 1 (Nadim et al., 1998; Bartos et al., 1999). The ability of one circuit to regulate and coordinate the activity of a related circuit by way of its synaptic influence on the activity pattern of a modulatory projection neuron provides a novel mechanism for how such regulation can occur.

Either of the two pyloric-influenced pathways alone was sufficient to enable the pyloric rhythm to regulate gastric mill cycle frequency and gastric mill-pyloric coordination. However, in the normal condition, when both pathways were present, some aspects of the gastric mill rhythm were regulated conjointly by both pathways whereas other aspects of this rhythm were patterned primarily by the pyloric-timed activity in MCN1. One example of the combined action of both pyloric-influenced pathways on the gastric mill rhythm was their influence on the LG neuron duty cycle. Either of these pathways alone was sufficient to maintain a steady LG neuron duty cycle, but neither one alone was sufficient to produce the same duty cycle that occurred when both pathways were present. Thus, because a given LG neuron duty cycle also defines the Int1 duty cycle for the gastric mill rhythm and these two neurons constitute the core of the gastric mill central pattern generator (Coleman et al., 1995; Bartos et al., 1999), these effects on LG neuron duty cycle indicate that neither pyloric pathway alone elicited the same gastric mill rhythm as did their combined influence. Changes in the LG neuron duty cycle represent a change in the fraction of each chewing cycle during which the teeth protract (LG neuron active) and retract (LG neuron inactive) (Heinzel et al., 1993). The behavioral relevance of this change in the chewing pattern, such as whether it underlies the chewing of different types of food, remains to be determined.

The combined influence of both pyloric-regulated pathways was also evident in the latency relationship that underlies the coordination of the pyloric and gastric mill rhythms. Although most LG neuron bursts were initiated during an episode of the rhythmic, pyloric-timed depolarizations it received during its interburst from MCN1, this MCN1 input consistently occurred at or near the peak of the immediately preceding pyloric-mediated disinhibition. It was therefore not surprising that separating these two pyloric-timed depolarizing events decreased the effectiveness of each one and thereby increased the latency to LG neuron burst onset, relative to both $\mathrm{AB}-\mathrm{PD}$ and MCN1 activity, and increased its variability.

An example of the selective influence of the pyloric-timed MCN1 activity on the gastric mill rhythm was the generation of pyloric-timed bursts in the LG neuron. Each pyloric-timed burst in the LG neuron occurred during the corresponding pylorictimed burst in MCN1 and resulted from MCN1-mediated excitation of the LG neuron. In contrast, when MCN1 was tonically active but the pyloric rhythm was still influencing the gastric mill rhythm via $A B$ inhibition onto Int1, each LG neuron burst was tonic. This change from a tonic to rhythmic LG burst pattern should change the protraction movements of the lateral teeth from a single smooth movement to fast rhythmic ones (Heinzel et al., 1993). When MCN1 is tonically active, each LG neuron burst is a consequence of both electrical and peptidergic input from MCN1 (Coleman et al., 1995; Wood et al., 2000). It will be interesting to determine whether there is a change in the balance of influence of the electrical and peptidergic actions when MCN1 activity is pyloric rhythm-timed.

The specific timing of MCN1 activity relative to the pyloric rhythm was not important to its influence on gastric mill cycle frequency. The MCN1 influence on gastric mill cycle frequency appeared to be determined primarily by the overall MCN1 firing frequency, insofar as tonic MCN1 activity at $25 \mathrm{~Hz}$ consistently elicited faster gastric mill rhythms than did pyloric-timed MCN1 activity with an intraburst firing rate of $25 \mathrm{~Hz}$ but an overall firing rate of $\sim 20 \mathrm{~Hz}$. Previous work showed that when MCN1 is tonically active, the speed of the gastric mill rhythm is directly correlated with MCN1 firing frequency (Bartos et al., 1999). These experiments also reinforced previous work documenting that the presence of a pyloric rhythm input always results in a faster gastric mill rhythm (Bartos et al., 1999). Here, the loss of AB neuron inhibition of Int 1 did not slow the gastric mill rhythm as long as MCN1 was pyloric-timed instead of being tonically active.

Our work revealing that the pyloric circuit has two pathways by which it regulates the gastric mill rhythm suggests that feedback processes might include redundant pathways. However, closer analysis has revealed that these multiple feedback loops act synergistically to maintain coordination between these circuits. Additionally, there is a shift in the relative influence of the two pyloric-related inputs during different gastric mill rhythms. One such distinct gastric mill rhythm results from the activation of either an identified mechanosensory pathway or a projection neuron located in the crab brain. Both of these inputs elicit a gastric mill rhythm driven primarily or entirely by coactivation of MCN1 and a second projection neuron, CPN2 (Beenhakker and Nusbaum, 2004; Beenhakker et al., 2004; Christie et al., 2004). During the MCN1-CPN2-elicited gastric mill rhythm, MCN1 activity remains pyloric-timed during the LG neuron interburst but it is tonically active during the LG neuron burst. Consequently, during this latter rhythm, the LG neuron burst is tonic instead of pyloric-timed. The presence of multiple feedback pathways also provides the possibility that there might be statedependent shifts in the balance of influence of the different feedback pathways caused by neuromodulation. For example, there are many different neuromodulators present in the STNS that alter the cellular and synaptic properties of the resident neurons (Nusbaum et al., 2001; Marder and Thirumalai, 2002).

Bidirectional communication between different levels is common in all types of neuronal circuits, but the role(s) of the feed- 
back pathways in most circuits remains to be determined (Sillito and Jones, 2002; Alitto and Usrey, 2003). Additional analysis of the interactions between different functional levels of the feeding-related motor circuits in the STNS will therefore inform investigators aiming to unravel the function of circuit feedback not only in other rhythmic motor systems but also in those involved in processing other types of information.

\section{References}

Alitto HJ, Usrey WM (2003) Corticothalamic feedback and sensory processing. Curr Opin Neurobiol 13:440-445.

Bartos M, Nusbaum MP (1997) Intercircuit control of motor pattern modulation by presynaptic inhibition. J Neurosci 17:2247-2256.

Bartos M, Manor Y, Nadim F, Marder E, Nusbaum MP (1999) Coordination of fast and slow rhythmic neuronal circuits. J Neurosci 19:6650-6660.

Beenhakker MP, Nusbaum MP (2004) Mechanosensory activation of a motor circuit by coactivation of two projection neurons. J Neurosci 24:67416750.

Beenhakker MP, Blitz DM, Nusbaum MP (2004) Long-lasting activation of rhythmic neuronal activity by a novel mechanosensory system in the crustacean stomatogastric nervous system. J Neurophysiol 91:78-91.

Blitz DM, Nusbaum MP (1997) Motor pattern selection via inhibition of parallel pathways. J Neurosci 17:4965-4975.

Blitz DM, Christie AE, Coleman MJ, Norris BJ, Marder E, Nusbaum MP (1999) Different proctolin neurons elicit distinct motor patterns from a multifunctional neuronal network. J Neurosci 19:5449-5463.

Cattaert D, Clarac F (1983) Influence of walking on swimmeret beating in the lobster Homarus gammarus. J Neurobiol 14:421-439.

Christie AE, Stein W, Quinlan JE, Beenhakker MP, Marder E, Nusbaum MP (2004) Actions of a histaminergic/peptidergic projection neuron on rhythmic motor patterns in the stomatogastric nervous system of the crab Cancer borealis. J Comp Neurol 469:153-169.

Clemens S, Combes D, Meyrand P, Simmers J (1998) Long term expression of two interacting motor pattern-generating networks in the stomatogastric system of freely behaving lobster. J Neurophysiol 79:1396-1408.

Coleman MJ, Nusbaum MP (1994) Functional consequences of compartmentalization of synaptic input. J Neurosci 14:6544-6552.

Coleman MJ, Nusbaum MP, Cournil I, Claiborne BJ (1992) Distribution of modulatory inputs to the stomatogastric ganglion of the crab, Cancer borealis. J Comp Neurol 325:581-594.

Coleman MJ, Meyrand P, Nusbaum MP (1995) A switch between two modes of synaptic transmission mediated by presynaptic inhibition. Nature 378:502-505.

Deliagina TG, Zelenin PV, Fagerstedt P, Grillner S, Orlovsky GN (2000) Activity of reticulospinal neurons during locomotion in the freely behaving lamprey. J Neurophysiol 83:853-863.

Dubuc R, Grillner S (1989) The role of spinal cord inputs in modulating the activity of reticulospinal neurons during fictive locomotion in the lamprey. Brain Res 483:196-200.

Frost WN, Katz PS (1996) Single neuron control over a complex motor program. Proc Natl Acad Sci USA 93:422-426.

Harris-Warrick RM, Marder E, Selverston AI, Moulins M (1992) Dynamic biological networks: the stomatogastric nervous system. Cambridge, MA: MIT.

Heinzel HG, Weimann JM, Marder E (1993) The behavioral repertoire of the gastric mill in the crab, Cancer pagurus: an in situ endoscopic and electrophysiological examination. J Neurosci 13:1793-1803.

Hooper SL, Marder E (1987) Modulation of the lobster pyloric rhythm by the peptide proctolin. J Neurosci 7:2097-2112.
Hooper SL, O’Neil MB, Wagner R, Ewer J, Golowasch J, Marder E (1986) The innervation of the pyloric region of the crab, Cancer borealis: homologous muscles in decapod species are differently innervated. J Comp Physiol [A] 159:227-240.

Kasicki S, Grillner S, Ohta Y, Dubuc R, Brodin L (1989) Phasic modulation of reticulospinal neurones during fictive locomotion and other types of spinal motor activity in lamprey. Brain Res 484:203-216.

Kawahara K, Kumagai S, Nakazono Y, Myamoto Y (1989) Coupling between respiratory and stepping rhythms during locomotion in decerebrate cats. J Appl Physiol 67:110-115.

Larson CR, Yajima Y, Ko P (1994) Modification in activity of medullary respiratory-related neurons for vocalization and swallowing. J Neurophysiol 71:2294-2304.

Marder E, Thirumalai V (2002) Cellular, synaptic and network effects of neuromodulation. Neural Netw 15:479-493.

Morin D, Viala D (2002) Coordination of locomotor and respiratory rhythms in vitro are critically dependent on hindlimb sensory inputs. J Neurosci 22:4756-4765.

Nadim F, Manor Y, Nusbaum MP, Marder E (1998) Frequency regulation of a slow rhythm by a fast periodic input. J Neurosci 18:5053-5067.

Nagy F, Cardi P, Cournil I (1994) A rhythmic modulatory gating system in the stomatogastric nervous system of Homarus gammarus. I. Pyloric-related neurons in the commissural ganglia. J Neurophysiol 71:2477-2489.

Norris BJ, Coleman MJ, Nusbaum MP (1994) Recruitment of a projection neuron determines gastric mill motor pattern selection in the stomatogastric nervous system of the crab, Cancer borealis. J Neurophysiol 72:1451-1463.

Norris BJ, Coleman MJ, Nusbaum MP (1996) Pyloric motor pattern modification by a newly identified projection neuron in the crab stomatogastric nervous system. J Neurophysiol 75:97-108.

Nusbaum MP, Beenhakker MP (2002) A small-systems approach to motor pattern generation. Nature 417:343-350.

Nusbaum MP, Kristan WB (1986) Swim-initiation in the leech by serotonincontaining interneurones, cells 21 and 61. J Exp Biol 122:277-302.

Nusbaum MP, Blitz DM, Swensen AM, Wood D, Marder E (2001) The roles of co-transmission in neural network modulation. Trends Neurosci 24:146-154

Perrins R, Weiss KR (1996) A cerebral central pattern generator in Aplysia and its connections with buccal feeding circuitry. J Neurosci 16:7030-7045

Robertson RM, Moulins M (1984) Oscillatory command input to the motor pattern generators of the crustacean stomatogastric ganglion. II. The gastric rhythm. J Comp Physiol [A] 154:473-491.

Sillito AM, Jones HE (2002) Corticothalamic interactions in the transfer of visual information. Philos Trans R Soc Lond B Biol Sci 357:1739-1752.

Suthers RA (1997) Peripheral control and lateralization of birdsong. J Neurobiol 33:632-652.

Weeks JC (1981) Neuronal basis of leech swimming: separation of swim initiation, pattern generation, and intersegmental coordination by selective lesions. J Neurophysiol 45:698-723.

Weimann JM, Marder E (1994) Switching neurons are integral members of multiple oscillatory networks. Curr Biol 4:896-902.

Weimann JM, Meyrand P, Marder E (1991) Neurons that form multiple pattern generators: identification and multiple activity patterns of gastric/ pyloric neurons in the crab stomatogastric system. J Neurophysiol 65:111-122.

Wood DE, Nusbaum MP (2001) A role for rhythmic activity in a modulatory projection neuron. Soc Neurosci Abstr 27:806.22.

Wood DE, Stein W, Nusbaum MP (2000) Projection neurons with shared cotransmitters elicit different motor patterns from the same neural circuit. J Neurosci 20:8943-8953. 